\title{
Article \\ Characterization of Prion Disease Associated with a Two-Octapeptide Repeat Insertion
}

\author{
Nicholas Brennecke ${ }^{1,+}{ }^{,}$Ignazio Cali ${ }^{2,3,+}$, Tze How Mok ${ }^{4}$, Helen Speedy ${ }^{4}$, \\ Genomics England Research Consortium ${ }^{5}$, Laszlo L. P. Hosszu ${ }^{4}$, Christiane Stehmann ${ }^{6} \mathbb{D}^{\mathbb{D}}$, Laura Cracco ${ }^{7}$, \\ Gianfranco Puoti ${ }^{8,9}$, Thomas W. Prior ${ }^{10}$, Mark L. Cohen ${ }^{1,2,3}$, Steven J. Collins ${ }^{6}$, Simon Mead ${ }^{4}$ (D) \\ and Brian S. Appleby 1,2,3,11,*(D)
}

check for updates

Citation: Brennecke, N.; Cali, I.; Mok, T.H.; Speedy, H.; Genomics England Research Consortium; Hosszu, L.L.P.; Stehmann, C.; Cracco, L.; Puoti, G.; Prior, T.W.; et al. Characterization of Prion Disease Associated with a Two-Octapeptide Repeat Insertion. Viruses 2021, 13, 1794. https:/ / doi.org/10.3390/v13091794

Academic Editor: Byron Caughey

Received: 2 August 2021

Accepted: 4 September 2021

Published: 8 September 2021

Publisher's Note: MDPI stays neutral with regard to jurisdictional claims in published maps and institutional affiliations.

Copyright: (c) 2021 by the authors. Licensee MDPI, Basel, Switzerland. This article is an open access article distributed under the terms and conditions of the Creative Commons Attribution (CC BY) license (https:// creativecommons.org/licenses/by/ $4.0 /)$.
1 Department of Neurology, Case Western Reserve University \& University Hospitals Cleveland Medical, Cleveland, OH 44106, USA; Nicholas.Brennecke@uhhospitals.org (N.B.); mlc11@case.edu (M.L.C.)

2 Department of Pathology, School of Medicine, Case Western Reserve University, Cleveland, OH 44106, USA; ixc20@case.edu

3 National Prion Disease Pathology Surveillance Center (NPDPSC), Cleveland, OH 44106, USA

4 MRC Prion Unit at University College London, Institute of Prion Diseases, London W1W 7FF, UK; tze.mok@ucl.ac.uk (T.H.M.); h.speedy@ucl.ac.uk (H.S.); 1.hosszu@prion.ucl.ac.uk (L.L.P.H.); s.mead@prion.ucl.ac.uk (S.M.)

5 Genomics England Limited of Dawson Hall, Charterhouse Square, London EC1M 6BQ, UK

6 Australian National Creutzfeldt-Jakob Disease Registry, The Florey Institute, The University of Melbourne, Melbourne, VIC 3010, Australia; christiane.stehmann@florey.edu.au (C.S.); s.collins@unimelb.edu.au (S.J.C.)

7 Department of Pathology and Laboratory Medicine, School of Medicine, Indiana University, Indianapolis, IN 46202, USA; lcracco@iu.edu

8 Department of Advanced Medical and Surgical Sciences, University of Campania "Luigi Vanvitelli", 81100 Caserta, Italy; Gianfranco.PUOTI@unicampania.it

9 Prion Disease Diagnosis and Surveillance Center (PDDSC), University of Campania "Luigi Vanvitelli", 81100 Caserta, Italy

10 Center for Human Genetics Laboratory, Case Western Reserve University \& University Hospitals Cleveland Medical Center, Cleveland, OH 44106, USA; thomas.prior@uhhospitals.org

11 Department of Psychiatry, Case Western Reserve University \& University Hospitals, Cleveland, $\mathrm{OH} 44106, \mathrm{USA}$

* Correspondence: bsa35@case.edu; Tel.: +216-368-0587; Fax: 216-368-4090

+ These authors contributed equally to this work.

Abstract: Genetic prion disease accounts for 10-15\% of prion disease. While insertion of four or more octapeptide repeats are clearly pathogenic, smaller repeat insertions have an unclear pathogenicity. The goal of this case series was to provide an insight into the characteristics of the 2-octapeptide repeat genetic variant and to provide insight into the risk for Creutzfeldt-Jakob disease in asymptomatic carriers. 2-octapeptide repeat insertion prion disease cases were collected from the National Prion Disease Pathology Surveillance Center (US), the National Prion Clinic (UK), and the National Creutzfeldt-Jakob Disease Registry (Australia). Three largescale population genetic databases were queried for the 2-octapeptide repeat insertion allele. Eight cases of 2-octapeptide repeat insertion were identified. The cases were indistinguishable from the sporadic Creutzfeldt-Jakob cases of the same molecular subtype. Western blot characterization of the prion protein in the absence of enzymatic digestion with proteinase $\mathrm{K}$ revealed that 2-octapeptide repeat insertion and sporadic Creutzfeldt-Jakob disease have distinct prion protein profiles. Interrogation of large-scale population datasets suggested the variant is of very low penetrance. The 2-octapeptide repeat insertion is at most a low-risk genetic variant. Predictive genetic testing for asymptomatic blood relatives is not likely to be justified given the low risk.

Keywords: prion disease; Creutzfeldt-Jakob disease; genetic Creutzfeldt-Jakob disease; genetics; octapeptide repeat insertion 


\section{Introduction}

Prion disease $(\mathrm{PrD})$ can be sporadic, genetic, or acquired. Genetic prion disease (gPrD) accounts for $10-15 \%$ of prion diseases and is caused by pathogenic sequence variations in the prion protein gene (PRNP) [1]. Most PRNP mutations are point mutations but deletions and insertions in the octapeptide repeat region of $P R N P$ are reported, referred to respectively as octapeptide repeat deletions (OPRDs) and octapeptide repeat insertions (OPRIs) [2]. The combination and number of repeats in OPRI mutations vary and are thought to contribute to phenotypic variation $[1,3,4]$. In this study, we sought to characterize the clinical features, histopathology, and molecular typing of the prion protein $(\mathrm{PrP})$ associated with 2-OPRI patients and to determine the risk for Creutzfeldt-Jakob disease (CJD) in carriers of the 2-OPRI variant.

The first case of the 2-OPRI in the setting of CJD was reported in 1993 [5]. The proband died of neuropathologically verified CJD 3 months after presenting with speech and language difficulties. Multiple first-degree family members were carriers of the 2-OPRI variant, including a family member with a long-standing history of dementia.

A second case of 2-OPRI in the setting of dementia was reported in 2000 [6]. The patient presented after years of progressive memory impairment. Genetic studies revealed a 2-OPRI variant with valine homozygosity at codon 129 of PRNP. No autopsy was performed. The patient did not have a family history suggestive of PrD.

A third case of 2-OPRI in the setting of dementia was reported in 2004 [4]. The patient developed dementia in their sixth decade of life and then declined over years to a mute state. Autopsy results were not reported. Genetic studies demonstrated heterozygosity at codon 129 of PRNP.

These reports have not provided a conclusion as to the significance of the 2-OPRI genetic variant. While OPRI mutations comprised of four or more repeats are clearly pathogenic in that the majority of mutation carriers develop prion disease in their lifetimes, the pathogenicity of smaller repeats has thus far remained unclear [2]. This paper presents a new collection of 2-OPRI cases in subjects with autopsy-confirmed prion disease and (or) clinical features that satisfy criteria for the classification of probable CJD. The hypothesis at the outset was that 2-OPRI was not a high penetrance mutation but rather a genetic variant that may modify the risk or phenotype of SCJD.

\section{Materials and Methods}

\subsection{Ethics Approval, Data Collection}

Multiple prion disease surveillance centers were queried as to whether or not they had subjects with 2-OPRI variants. Three national prion disease surveillance centers replied that they had subjects with the 2-OPRI variant in their database and agreed to partake in this study. Eight cases were identified from the USA $(n=5)$, the UK $(n=2)$, and Australia $(n=1)$. After an Institutional review board (IRB) review from University Hospitals Cleveland Medical Center (STUDY20201625), the Scotland A Research Ethics Committee (REC code 05/MRE00/63), and the University of Melbourne Human Research Ethics Committee (ethics approval number 1341074), records were reviewed and data were collected on PRNP codon 129 polymorphism, family history of $\operatorname{PrD}$, and other neurodegenerative diseases, gender, ethnicity, age at symptom onset, symptom progression, disease duration, brain magnetic resonance imaging (MRI) findings, electroencephalogram (EEG) findings, cerebrospinal fluid (CSF) test results, neuropathologic findings, and prion protein chemistry results (Western blot). CSF testing was conducted as per each country's protocol [7-10]. Brain MRIs were evaluated using criteria from Zerr and colleagues [11]. Each case was deemed to represent either definite or probable CJD, depending on the presence or absence of autopsy, respectively. Data from all cases were abstracted using the same instrument.

\subsection{Genetic Testing}

PRNP genetic testing was performed within each surveillance center as previously described [12,13]. PRNP was examined for sequence variations and the repeat sequence 
in the octapeptide region of the gene were noted, if available, as previously described by Goldfarb and colleagues [14]. Codon 129 polymorphism was also described for each case.

\subsection{Reagents and Antibodies}

For the USA, Proteinase K (PK), phenylmethanesulfonyl fluoride (PMSF), $10 \times$ Dulbecco's Phosphate Buffered Saline (DPBS) were from Sigma-Aldrich (St. Louis, MO, USA). Laemmli Sample Buffer, Tween 20, and 15\% Criterion ${ }^{\mathrm{TM}}$ Tris- $\mathrm{HCl}$ protein gels were from Bio-Rad Laboratories (Hercules, CA, USA). Blocking buffer and Infrared Dye 800CW goat anti-mouse IgG $(1 \mathrm{mg} / \mathrm{mL})$ were from LI-COR Biosciences (Lincoln, NE, USA). Polyvinylidene fluoride (PVDF) membrane (Immobilon-FL) was from EMD Millipore (Billerica, MA, USA). The monoclonal 3F4 antibody (Ab) to PrP, epitope 106-110, was used [15,16]. The UK followed previously published protocols [12].

\subsection{Brain Tissue}

Brain autopsy of USA patients with 2-OPRI $(N=5)$, controls SCJDMM1 $(N=2)$, and SCJDMM2 $(N=1)$ was performed at the NPDPSC in Cleveland, Ohio. The autopsy of the 7OPRI case was carried out at the Prion Disease Diagnosis and Surveillance Center (PDDSC) in the Department of Advanced Medical and Surgical Sciences, University of Campania "Luigi Vanvitelli" (Caserta, Italy) [17,18]. The molecular (Cali I.) and histopathological (Cali I. and Cohen M.L.) study of US cases were done at the NPDPSC. Brain regions examined by Western blotting included the frontal cortex (2-OPRI cases 1-5 of Table 1, 7-OPRI, sCJD controls), occipital cortex (2-OPRI cases 1 and 3), and cerebellum (2-OPRI cases 1-5). Brain autopsy and histopathological examination of the UK patient were performed at the National Hospital for Neurology and Neurosurgery on Queen Square, London. The molecular strain typing and Western Blot were performed on frozen frontal cortex at the MRC Prion Unit at UCL [19].

\subsection{Histology and PrP Immunohistochemistry}

For the USA cases, the formalin-fixed brain was treated as previously described [18]. Tissue was deparaffinized, rehydrated, and immersed in Tween 20-Tris buffered saline. The endogenous peroxidase was blocked by the Envision Flex Peroxidase Blocking Reagent (Dako North America Inc., Carpinteria, CA, USA) for $10 \mathrm{~min}$, which was followed by several washes. Sections were immersed in hydrochloric acid $(1.5 \mathrm{mmol} / \mathrm{L})$, microwaved for $15 \mathrm{~min}$, and incubated with purified 3F4 Ab (1:1000) for 1 hour. Sections were washed and incubated with Envision Flex/HRP polymer for 30 min (Dako). The Envision Flex DAB (Dako) was used to show the immunostaining. Brain tissue blocks from the only UK-autopsied case were from 1985 and not suitable for modern immunocytochemistry.

\subsection{Preparation of Brain Homogenates and Detergent-Insoluble Fractions}

For the USA cases, frozen brain material was homogenized in $1 \times$ Lysis buffer (LB100) $(100 \mathrm{mM} \mathrm{NaCl}, 0.5 \%$ Nonidet P-40, 0.5\% sodium deoxycholate, $10 \mathrm{mM}$ EDTA, $100 \mathrm{mM}$ Tris- $\mathrm{HCl}$, $\mathrm{pH}$ 8.0) [20]. The resulting $10 \% \mathrm{BH}$ was subjected to low speed centrifugation $(1000 \times g)$ for $5 \mathrm{~min}$ at $4{ }^{\circ} \mathrm{C}$ and the supernatant (S1) was collected. Aliquots of S1 from the five USA cases were further subjected to high speed centrifugation $(100,000 \times g)$ for $1 \mathrm{~h}$ at $4{ }^{\circ} \mathrm{C}$ to generate the detergent-insoluble disease-associated $\operatorname{PrP}\left(\operatorname{PrP}^{\mathrm{D}}\right)$, which was resuspended in $1 \times \mathrm{LB100} \mathrm{pH}$ 8.0. Detergent insoluble $\operatorname{PrP}^{\mathrm{D}}$ samples were obtained from the frontal cortex of (i) 2-OPRI with methionine (M) homozygosity at codon 129 (129MM) and PK-resistant $\operatorname{PrP}^{\mathrm{D}}\left(\right.$ resPrP $\mathrm{P}^{\mathrm{D}}$ ) type 1 (2-OPRI-MM1; $n=3$ ), (ii) 7-OPRI with 129MM genotype and resPrPD type 1 (7-OPRI-MM1; $n=1)$, and (iii) $\operatorname{sCJDMM1~}(n=2)$.

\subsection{Proteinase K Digestion and Western Blot (WB) Analysis}

For the USA cases, $\mathrm{S} 1$ were treated with 10 units $/ \mathrm{mL}(\mathrm{U} / \mathrm{mL}) \mathrm{PK}(48 \mathrm{U} / \mathrm{mg}$ specific activity, $1 \mathrm{U} / \mathrm{mL}$ equal to $20.8 \mu \mathrm{g} / \mathrm{mL}$ PK) at $37^{\circ} \mathrm{C}$ for $1 \mathrm{~h}$. The reaction was stopped by addition of PMSF $(3 \mathrm{mM})$. Each sample was mixed with an equal volume of $2 \times$ Laemmli buffer 
and boiled at $100{ }^{\circ} \mathrm{C}$ for $10 \mathrm{~min}$. Proteins were loaded onto a $15 \%$ Tris- $\mathrm{HCl}$ Criterion ${ }^{\mathrm{TM}}$, $8.7 \mathrm{~cm}$-long gels. Western blot analysis was performed as previously described [21,22]. The $\mathrm{Ab} 3 \mathrm{~F} 4$ was used at 1:10,000 dilution. Membranes were developed by the Odyssey nearinfrared imaging system (LI-COR Biosciences) and densitometric analysis was performed with the Odyssey software V3.0 (LI-COR Biosciences). Most of the WB were performed in triplicate. Typing of resPrP $\mathrm{P}^{\mathrm{D}}$ of cases obtained at the NPDPSC was assessed using the "Parchi et al." molecular classification [23,24]. For clarity, in this manuscript, the UK resPrP $\mathrm{P}^{\mathrm{D}}$ was converted to the same typing classification, according to "Parchi et al.".

\subsection{Penetrance Estimation}

Three largescale population genetic databases were queried for the 2-OPRI allele: gnomAD v2.1.1 (USA), gnomAD v3 (USA), and 100,000 Genomes Project (UK). The total allele counts used for penetrance calculations from the gnomAD v2.1.1 and v3 datasets were 279,320 (range 247,484-279,320) and 142,740 (range 141,382-142,740), respectively, while the total allele count for the 100,000 Genomes Project was 66,670. The upper ends of the total allele counts from gnomAD v2.1.1 and v3 were used in the calculations. Within these 3 datasets, assertion of unaffected status is secure in the 100,000 Genomes Project, as both 2-OPRI alleles originate from individuals within non-neurological cohorts. However, this is not the case for the gnomAD datasets as variant-phenotype data are not routinely available and confirmed to not be shareable following official enquiries. The list of contributing cohorts to the gnomAD datasets include Alzheimer's disease, migraine, and psychiatry cohorts, which cannot be deemed strictly non-neurological.

The central estimate of disease penetrance is equal to the proportion of individuals with the disease who have the genotype (no. of 2-OPRI alleles found in CJD cases $\div$ all $P R N P$-sequenced CJD cases) multiplied by the prevalence of the disease (lifetime risk of CJD $(0.02 \%))$, and divided by the frequency of the genotype in the general population (no. of 2-OPRI alleles found in a specific dataset $\div$ number of $P R N P$ alleles sequenced in that particular dataset) $[25,26]$. The Wilson Interval is best used to calculate the $95 \%$ confidence interval here as the central estimate is close to zero.

$$
\begin{gathered}
\text { Penetrance }=\frac{\text { lifetime CJD risk } x \text { frequency of } 2 O P R I \text { allele in CJD cases }}{\text { frequency } 2 O P R I \text { allele in normal population }} \\
\text { Penetrance }=\frac{\text { lifetime CJD risk } x(2 O P R I \text { alleles in } C J D \text { cases } \div \text { no.of sequence PRNP CJD alleles })}{(2 O P R I \text { alleles in genetic dataset } \div \text { no.of sequenced PRNP alleles in genetic dataset })}
\end{gathered}
$$

\section{Results}

\subsection{Clinical Features and Genetics}

Eight cases were compiled, and clinical data is shown in Table 1. All cases were of white race. The median age at onset was 75 years (range $58-84$ years, mean 71 years \pm 8.1 ). The age at disease onset was known for six cases and mean age at onset differed significantly between methionine homozygotes and heterozygotes at codon 129 (64.3 \pm 5.5 and $78.0 \pm 5.3$, respectively, $t$-test, $p=0.036$ ). The median disease duration was 7 months (range 2-21 months). All cases with known dates of onset had an illness duration of 7 months or less, with the exception of one case of probable CJD that had an illness duration of 21 months. Family history is relevant because highly penetrant mutations typically show an autosomal dominant inheritance pattern in pedigrees, whereas low penetrance variants might only rarely cause CJD in relatives. Family history of neurodegenerative disease was noted in three cases. No cases had a family history of prion disease. The clinical phenotype of the 2-OPRI cases was heterogenous but marked by typical CJD features, including dementia, ataxia, pyramidal signs, myoclonus, and visual symptoms. One case demonstrated periodic sharp wave complexes on an electroencephalogram. Brain MRIs were obtained in all but one case and were consistent with PrD: all MRIs demonstrated cortical hyperintensity on diffusion weighted imaging (DWI), while three of seven cases demonstrated hyperintensity in the basal ganglia. All but one case demonstrated a positive 14-3-3 in the 
CSF. The mean CSF tau value was 12,402 pg/mL (high tau levels, e.g., >1500 pg/mL, are suggestive of prion disease) [8]. All cases tested by real time quaking-induced conversion (RT-QuIC) were positive. All cases demonstrated two repeats in the octapeptide region of $P R N P$. Repeat sequences were available in seven cases: Most cases demonstrated repeats in R2-R2 (Table 2). Five cases were homozygous for methionine at codon 129. Three cases were methionine-valine heterozygous.

Table 1. Clinical presentation of 2-OPRI cases.

\begin{tabular}{|c|c|c|c|c|c|c|c|c|c|c|c|c|c|c|}
\hline Case & Origin & Diagnosis & $\begin{array}{c}\text { Codon } \\
129 \\
\text { Genotype }\end{array}$ & $\begin{array}{c}\text { resPrP }{ }^{\mathrm{D}} \\
\text { Type }^{\mathrm{a}}\end{array}$ & $\begin{array}{l}\text { Age at } \\
\text { Onset } \\
\text { (Years) }\end{array}$ & $\begin{array}{c}\text { Disease } \\
\text { Duration } \\
\text { (Months) }\end{array}$ & Gender & $\begin{array}{c}\text { 14-3-3 } \\
\text { Protein }\end{array}$ & $\begin{array}{c}\text { Tau } \\
(\mathrm{pg} / \mathrm{mL})^{b}\end{array}$ & $\begin{array}{l}\text { RT- } \\
\text { QuIC }\end{array}$ & $\begin{array}{c}\text { PSWC } \\
\text { on } \\
\text { EEG }\end{array}$ & $\begin{array}{l}\text { MRI } \\
c / w \\
C J D\end{array}$ & Family History & Clinical Phenotype \\
\hline 1 & us & Definite & MM & 1 & 67 & 2 & Male & Pos. & 17,727 & NA & $\mathrm{NA}$ & Yes & None & $\begin{array}{l}\text { Slurred speech, then a } \\
\text { fulminant course } \\
\text { including cognitive and } \\
\text { cerebellar symptoms } \\
\text { and myoclonus }\end{array}$ \\
\hline 2 & US & Probable & MM & 1 & NA & NA & Male & Pos. & 8848 & NA & $\mathrm{NA}$ & Yes & None & NA \\
\hline 3 & US & Definite & MM & 1 & 68 & 7 & Female & Pos. & 7990 & NA & Yes & Yes & $\begin{array}{l}\text { Mother with several } \\
\text { year slowly } \\
\text { progressive dementia } \\
\text { in her } 60 \text { s, thought to } \\
\text { be AD }\end{array}$ & $\begin{array}{l}\text { Absence-like episodes, } \\
\text { followed } 5 \text { months later by } \\
\text { cognitive symptoms, } \\
\text { personality change, } \\
\text { and myoclonus }\end{array}$ \\
\hline 4 & US & Probable & MV & $1-2$ & 84 & 3 & Female & Unk. & Unk. & NA & NA & Yes & None & $\begin{array}{l}\text { Myoclonus, unilateral } \\
\text { weakness/spasticity, late } \\
\text { cognitive symptoms }\end{array}$ \\
\hline 5 & US & Definite & MM & $1-2$ & $\mathrm{NA}$ & NA & Female & Pos. & 15,046 & Pos. & $\mathrm{NA}$ & Yes & None & NA \\
\hline 6 & UK & Probable & MV & $\mathrm{NA}$ & 76 & 10 & Male & Neg. & Unk. & Pos. & No & Yes & $\begin{array}{l}\text { Sister with 2-year } \\
\text { history of Alzheimer's } \\
\text { dementia starting at } \\
\text { age } 89 \text {; sister with mild } \\
\text { dementia in her } 80 \mathrm{~s} \text {. }\end{array}$ & $\begin{array}{l}\text { Gait ataxia, followed by } \\
\text { cognitive symptoms, } \\
\text { visual hallucinations, } \\
\text { and myoclonus }\end{array}$ \\
\hline 7 & UK & Definite & MM & 1 & 58 & 7 & Male & Unk. & Unk. & NA & No & NA & Unknown & $\begin{array}{l}\text { Right hand paresthesia } \\
\text { followed by unilateral } \\
\text { weakness/spasticity }\end{array}$ \\
\hline 8 & $\mathrm{AU}$ & Probable & MV & $\mathrm{NA}$ & 74 & 21 & Female & Pos. & Unk. & Pos. & No & Yes & $\begin{array}{l}\text { Brother with 5-year } \\
\text { history of dementia in } \\
\text { his } 60 \text { s. }\end{array}$ & $\begin{array}{l}\text { Visual disturbances, } \\
\text { followed by gait } \\
\text { disturbance, Parkinsonian } \\
\text { features, apraxia, and } \\
\text { visuospatial difficulties }\end{array}$ \\
\hline
\end{tabular}

${ }^{a}$ Parchi et al. classification [24]; ${ }^{b}$ high tau levels, e.g., $>1150 \mathrm{pg} / \mathrm{mL}$, are suggestive of prion disease [8]; resPrP ${ }^{\mathrm{D}}$ : PK-resistant diseaseassociated PrP; Codon 129 polymorphism in cis with the 2-OPRI mutation is underlined if known. US: United States; UK: United Kingdom; AU: Australia; RT-QuIC: real-time quaking-induced conversion; Pos.: positive; Neg.: negative; Unk.: unknown; PSWC: periodic sharp wave complexes; NA: not available; AD: Alzheimer's disease.

Table 2. Molecular features and histotype of 2-OPRI cases.

\begin{tabular}{|c|c|c|c|c|}
\hline Case Number & Codon 129 Genotype & Repeat Sequence $^{a}$ & resPrP ${ }^{D}$ Type $^{b}$ & sCJD Histotype $^{b}$ \\
\hline 1 & MM & R1-R2-R2-R2-R2-R3-R4 & 1 & $\mathrm{MM}(\mathrm{MV}) 1$ \\
\hline 2 & MM & R1-R2-R2-R3-R2-R3-R4 & 1 & $\mathrm{MM}(\mathrm{MV}) 1$ \\
\hline 3 & MM & R1-R2-R2-R2-R2-R3-R4 & 1 & $\mathrm{MM}(\mathrm{MV}) 1$ \\
\hline 4 & MV & R1-R2-R2-R2-R2-R3-R4 & $1-2$ & $\mathrm{MV} 2 \mathrm{C}+1^{\mathrm{c}}$ \\
\hline 5 & MM & R1-R2-R2-R3-R2a-R2a-R4 & 1 & MM1-2 \\
\hline 6 (UK) & MV & R1-R2-R2-R2-R2-R3-R4 & NA & NA \\
\hline 7 (UK) & MM & R1-R2-R2-R3-R2a-R2a-R4 & 1 & MM(MV)1. \\
\hline 8 (AUS) & MV & & NA & NA \\
\hline
\end{tabular}

a As defined by Goldfarb et al. [14]; ${ }^{\mathrm{b}}$ Parchi et al. classification [24]; c Minor sCJDMM2 component affecting the temporal cortex; Codon 129 polymorphism in cis with the 2-OPRI mutation is underlined if known. resPrPD: PK-resistant disease-associated PrP; MM: methionine homozygosity; MV: methionine/valine heterozygosity; NA: not available.

\subsection{Histopathology and Immunohistochemistry}

Neuropathology was available in six out of eight cases. Four out of five cases demonstrated classic spongiform degeneration (SD) and reactive astrocytosis on hematoxylin and eosin staining with a synaptic pattern of PrP deposition on immunohistochemical examination (cases 1-3 and 7, Table 2) (Figure 1). These histopathological features matched those associated with sCJDMM(MV)1. case 5 demonstrated the sCJDMM1-2 histotype with a minor type 2 component, characterized by large vacuoles and perivacuolar $\operatorname{PrP}$ 
deposition in the temporal cortex. case 4, carrying the $129 \mathrm{MV}$ genotype and resPrP $\mathrm{P}^{\mathrm{D}}$ type $1-2$, showed mild SD with small and large vacuoles, and diffuse and coarse PrP deposits within the neocortex. No features suggestive of gPrD, such as filamentous PrP deposits in the subcortical white matter or "striped" cerebellar PrP staining characteristic of some OPRIs, were observed in the autopsied brains $[27,28]$.

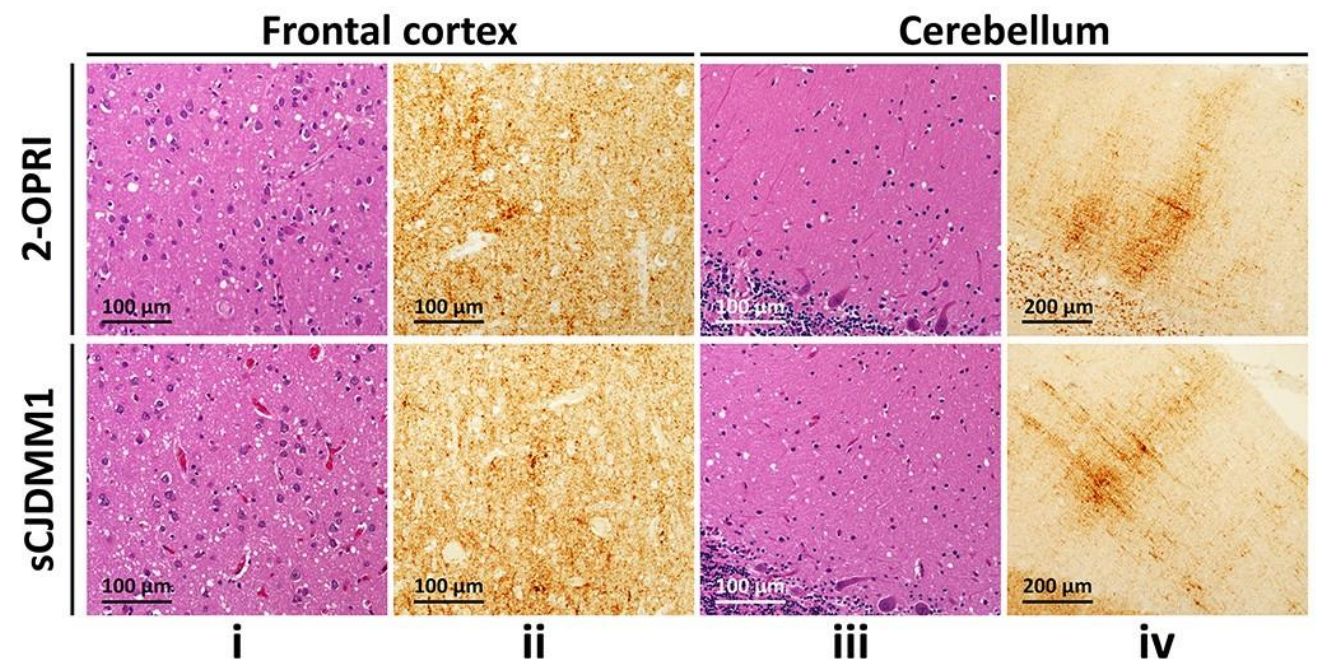

Figure 1. Histological determination of 2-OPRI and SCJDMM1: (i,iii): Hematoxylin-eosin staining. (ii,iv): PrP immunohistochemistry. (i,iii): Fine spongiform degeneration. (ii,iv): Diffuse PrP immunostaining (ii,iv) with the typical "brush stroke-like" deposits in the cerebellar molecular layer (iv); antibody: 3F4.

\subsection{Characterization of Detergent-Insoluble and PK-Resistant $\operatorname{Pr} P^{D}\left(\right.$ resPrP $\left.P^{D}\right)$}

Total PrP of the 2-OPRI (cases 2-4) showed several fragments spanning from $\sim 26$ to $\sim 35 \mathrm{kDa}$. Thus, the PrP profile of 2-OPRI differed markedly from that of sCJD, which consisted of three major bands corresponding to di- $(\sim 33 \mathrm{kDa})$, mono- $(\sim 31 \mathrm{kDa})$, and un-glycosylated $(\sim 27 \mathrm{kDa})$ PrP isoforms (Figure $2 \mathrm{~A})$. Following high-speed centrifugation, we generated detergent-insoluble $\mathrm{PrP}^{\mathrm{D}}$. Western blot analysis demonstrated that most of the PrP fragments of the 2-OPRI cases are detergent-insoluble and that most of them (e.g., $29,30,32 \mathrm{kDa}$, and a doublet of $\sim 34-35 \mathrm{kDa}$ ) are not detectable in sCJD. (Figure $2 \mathrm{~B}$ ). Furthermore, the 2-OPRI $\operatorname{PrP}^{\mathrm{D}}$ profile was different from that observed in a 7-OPRI case. Notably, the $\sim 34-35 \mathrm{kDa}$ doublet appeared as a triplet in the 7-OPRI case, while a band with the molecular weight of $\sim 42-44 \mathrm{kDa}$ was not detected in 2-OPRI (Figure 2C) [18]. Following digestion with $\mathrm{PK}$, the Western blot profile of resPrP $\mathrm{P}^{\mathrm{D}}$ from the OPRI and sCJD cases became virtually indistinguishable $[18,29,30]$.

\subsection{Estimation of 2-OPRI Penetrance}

Interrogation of a number of available large-scale population genetic datasets identified a total of sixteen 2-OPRI alleles in presumably unaffected individuals. Within these 16 alleles, 6 (5 exomic, 1 genomic) were from gnomAD v2.1.1 (USA), 8 from gnomAD v3 (USA), and 2 from the 100,000 Genomes Project (UK) [31]. Of the 14 alleles from the gnomAD datasets, 7 were non-Finnish Europeans, 4 were Finnish Europeans, 1 was South Asian, and 1 was African and 1 Latino/admixed American; 8 were male and 6 were female. Age range data was available for 5 of 6 gnomAD v2.1.1 cases only, with 2 cases in the 55-60 years range, 2 cases in the 60-65 year range, 1 case in the 65-70 years age range, and unknown for 1; age range data for gnomAD v3.1.1 is available for 2 of 8 cases, with 1 case in the 65-70 years age range and 1 case in the 70-75 years age range. Estimation of 2-OPRI penetrance and 95\% CI using a Bayesian approach and Wilson interval, respectively, revealed an extremely low penetrance of $0.3 \%$ and below, and upper bounds of $95 \% \mathrm{CI}$ below $2 \%$ [25]. Specifically, the estimated penetrance by leveraging the gnomAD v2.1.1 
was $0.34 \%(95 \%$ CI $0.08,1.46)$, gnomAD v3 was $0.13 \%$ (95\%CI $0.03,0.51)$, and, for the 100,000 Genomes Project, it was $0.24 \%$ (95\%CI 0.03, 1.75).
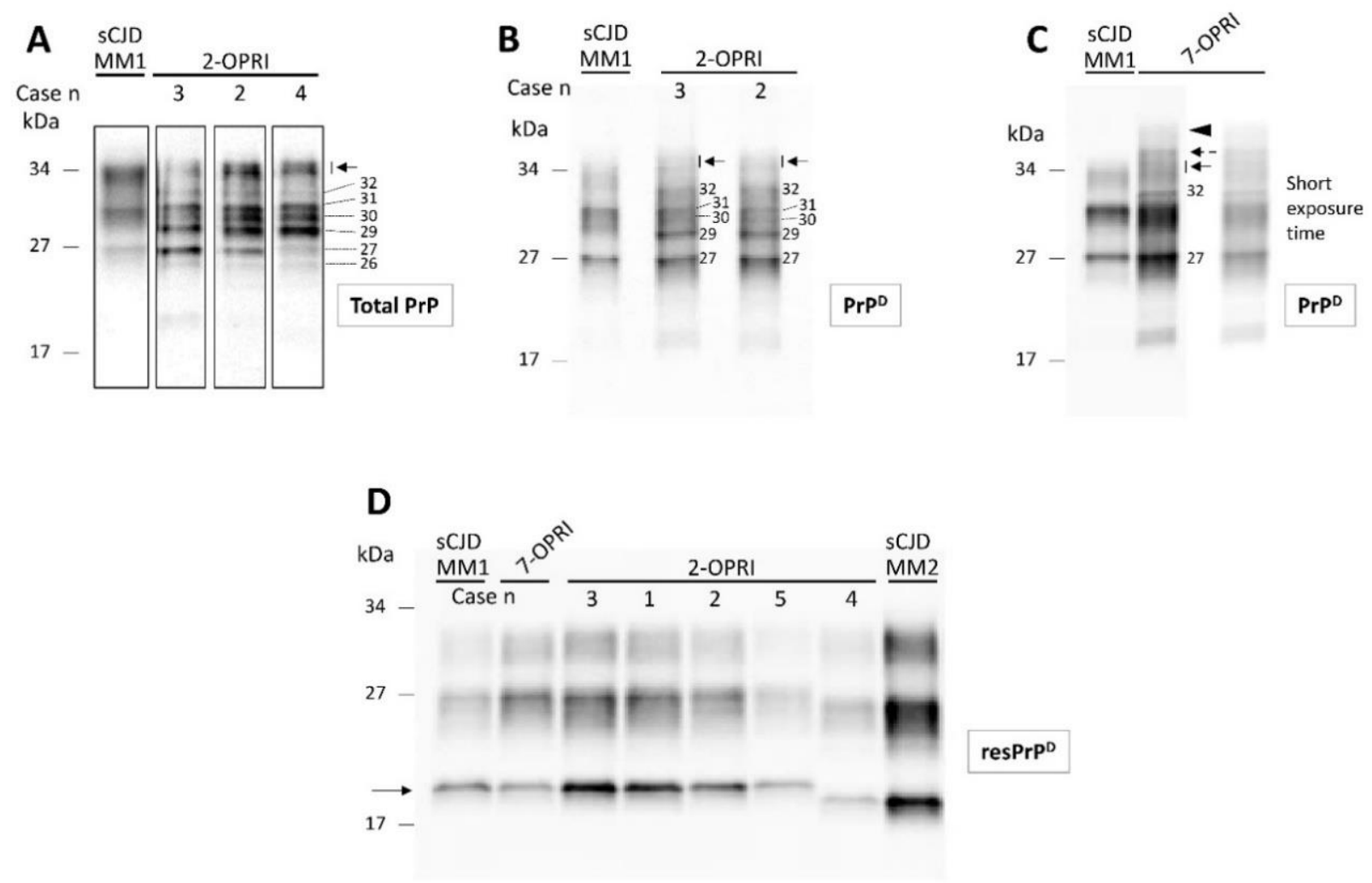

Figure 2. Western blot profiles of total $\operatorname{PrP}$, detergent-insoluble $\operatorname{Pr} \mathrm{P}^{\mathrm{D}}$ and $\operatorname{res} \mathrm{PrP}^{\mathrm{D}}$ : Samples harvested from the cerebral cortex were probed with the anti-PrP antibody 3F4. (A): Total PrP showing a complex PrP profile in 2-OPRI cases but not in sCJDMM1. The approximate molecular size of each band is indicated by the numbers on the right; arrow: PrP doublet of 34-35 kDa. (B): Western blot (WB) profile of detergent-insoluble PrPD harvested from 2-OPRI resembles that of total PrP except for the absence and weak presence of the $\sim 26$ and $\sim 30 \mathrm{kDa}$ fragments, respectively. (C): Insoluble PrP $\mathrm{P}^{\mathrm{D}} \mathrm{WB}$ profile of a 7-OPRI features a sharp band of $\sim 32 \mathrm{kDa}$, a $\operatorname{PrP}^{\mathrm{D}}$ triplet in the $\sim 34-36 \mathrm{kDa}$ region, and a $\operatorname{PrP}^{\mathrm{D}} \mathrm{smear}$ of $\sim 42-44 \mathrm{kDa}$, whereas the $\mathrm{PrP}^{\mathrm{D}}$ region of $\sim 31$ to $27 \mathrm{kDa}$ resembles that of sCJDMM1. (D): The un-glycosylated isoform of resPrP $\mathrm{P}^{\mathrm{D}}$ (arrow) in 2-OPRI-MM1 (cases 1-3), 2-OPRI-MM1-2 (case 5), and 7-OPRI-MM1 migrates to $20 \mathrm{kDa}$, matching the gel mobility of resPrP ${ }^{\mathrm{D}}$ type 1 (sCJDMM1). The un-glycosylated resPrP $\mathrm{P}^{\mathrm{D}}$ of 2-OPRI-MV1-2 (case 4) migrates to $\sim 19 \mathrm{kDa}$, thus matching the gel mobility of sCJDMM2 resPrP $\mathrm{P}^{\mathrm{D}}$ type 2 .

\section{Discussion}

The landscape of $\mathrm{gPrD}$ genetic variants and clinicopathological phenotypes is heterogeneous. Penetrance varies between PRNP mutations and some genetic variants affect disease risk and phenotypes but are not truly pathogenic (e.g., codon 129 polymorphism). As genetically-based treatment trials are on the horizon, estimating the penetrance of PRNP mutations is increasingly important [32]. In cases of PRNP OPRI variants, those with four or less extra repeats tend to resemble a CJD phenotype, while those with larger repeat insertions often suffer for longer durations and (or) a Gerstmann-Sträussler-Scheinker syndrome phenotype [1]. Little is known about prion disease associated with the lowest number of repeats in the octapeptide region.

In this study, we present clinicopathological and genetic data on eight 2-OPRI cases from three different countries. A variety of typical features were reported in cases with clinical data, and the median illness duration was 7 months, all of which were consistent with a classic CJD phenotype. Case 8 was an outlier with regard to protracted disease duration, passing away 21 months after symptom onset. This case was not autopsy confirmed, but met the criteria for probable CJD. Cases 6 and 8, which were both heterozygous at 
PrP codon 129, had the longest disease duration. Although data on $\operatorname{PrP}^{\mathrm{D}}$ type was not available for these two cases, the long disease duration suggests the presence of type 2 or mixed types 1 and 2 [33]. Age at disease onset was typical for sCJD. The length of OPRI in combination with PRNP codon 129 genotype has been used to explain variation in age at onset, as observed in a previously published OPRI case series [4]. We found a similar association in our 2-OPRI series, with codon 129 methionine homozygotes having a younger mean age at onset compared to heterozygotes. Only three cases had a family history of neurodegenerative disease, with all three being non-suggestive of a prion disease phenotype, and no cases had a family history of prion disease.

Neuropathological findings were consistent with what is observed in SCJD. Cases 1-3, 5, and 7-all methionine homozygous at $\operatorname{PrP}$ codon 129-showed the $\mathrm{SCJDMM}(\mathrm{MV}) 1$ histotype. A minor sCJDMM2 component was observed in the temporal lobe of case 5 [22]. In case 4 , neuropathological changes were characterized by diffuse and coarse $\operatorname{PrP}$ deposition and resembled the sCJDMV2C +1 histotype [33]. Although the wet tissue of the cerebellum was not available, Western blot analysis of the same brain region detected resPrP ${ }^{\mathrm{D}}$ type 1 , which reinforces the diagnosis of $\mathrm{MV} 2 \mathrm{C}+1$.

The PK-untreated PrP Western blot profile from the five U.S. 2-OPRI cases significantly differed from that of SCJDMM1 and other SCJD subtypes (Figure 2). Furthermore, the total $\operatorname{PrP}$ and detergent-insoluble $\mathrm{PrP}^{\mathrm{D}}$ of the 2-OPRI cases were similar except for variations in the prevalence of PrP fragments. Thus, although 2-OPRI cases and SCJD cases share histopathological features, they show distinct PrP profiles only in absence of proteolytic digestion.

Estimations of 2-OPRI penetrance by leveraging large-scale population genetic datasets in the USA and UK uniformly resulted in very low lifetime risks of between 0.13 and $0.24 \%$, with upper bounds of $95 \% \mathrm{CI}$ of $1.75 \%$. For comparison, the estimated lifetime risk of developing prion disease in the United States is 1:6239 or 0.016\%, suggesting an $\sim 8-15$-fold increase in risk above background [34]. The relative abundance of 2-OPRI alleles in these datasets produced narrow $95 \%$ CIs, thus avoiding the potential pitfall of underestimating the $95 \% \mathrm{CI}$ upper bound that afflicts novel sequence variants of a very low frequency such as singletons $[25,26]$. Of note, since large-scale datasets such as gnomAD and the 100,000 Genomes Project comprise data produced using short-read sequencing technologies, with read lengths of up to $150 \mathrm{bp}$, it is likely that 2-OPRI allele frequency in these datasets, and as such in the general population, is underestimated. While the normal octapeptide repeat region is 123 base pairs long, 2-OPRI alleles are 171 base pairs long, meaning that short sequencing reads are unable to fully resolve the spectrum of OPRI alleles present. 2-OPRI is different from highly penetrant mutations of PRNP, which make CJD inevitable or highly likely in a lifetime; rather, the 2-OPRI mutation increases the risk of CJD, but only to the extent that the lifetime risk for carriers is approximately 1 in 500 .

Most of the pathogenic mutations seen in inherited prion disease occur within residues 89-231 of PrP [35,36], which form the relatively protease-resistant core of the diseaseassociated form of $\mathrm{PrP}^{\mathrm{D}}$, and are sufficient to support prion replication and the development of pathology [37]. The octapeptide repeat insertions or deletions are the exception $[35,36]$. The mechanism by which the octapeptide repeat region influences the formation of $\operatorname{PrP}^{\mathrm{D}}$ is unclear, especially since this section of the protein is unfolded and highly mobile in the normal cellular form of $\operatorname{PrP}\left(\mathrm{PrP}^{\mathrm{C}}\right)$ and is rapidly digested by proteinase $\mathrm{K}$ in $\mathrm{PrP}^{\mathrm{D}}$ [38]. $\mathrm{PrP}$ is known to bind a range of divalent metal cations, including $\mathrm{Cu}^{2+}$ and $\mathrm{Zn}^{2+}$, with sub-stoichiometric quantities of $\mathrm{Cu}^{2+}$, causing self-association of the prion protein in vitro [39], suggesting that $\mathrm{Cu}^{2+}$ may play a role in controlling oligomerisation in vivo. The histidine residues of the octapeptide repeats, together with two histidines at residues 96 and 111, contribute to its $\mathrm{Cu}^{2+}$-binding properties. Thus, an expanded or contracted octapeptide region may affect $\mathrm{PrP}$ metal co-ordination and folding, or affect a metal-dependent function of $\mathrm{PrP}^{\mathrm{C}}$, with 4-OPRI or greater being required to significantly affect PrP metal co-ordination and pathology. 
This report has several limitations. Clinical data were absent in two cases, limiting conclusions on effect of the PRNP codon 129 genotype on variation in age at onset. Neuropathological data were absent in two cases. The conclusions are limited by sample size. Ascertainment bias may arise from the sole focus in obtaining detailed clinical PRNP sequencing and autopsied brain material from those presenting to prion disease surveillance centers. The dichotomous phenotypes of CJD and long-duration dementia syndromes are well-described even within the same pedigrees in larger OPRIs, most notably in 4- and 5-OPRI families [40,41]; furthermore, the penetrance in these pedigrees are notoriously incomplete, and ages of onset can be extremely variable. In our 2-OPRI case series, three patients had immediate blood relatives with long-duration neurodegenerative disease presumed to be non-prion disease etiologies such as Alzheimer's disease, but none of them underwent PRNP sequencing, and no autopsied brain material was examined to exclude prion pathology. If $\operatorname{PrD}$ neuropathology was identified in these relatives with long-duration neurodegenerative disease syndromes, this line of evidence would have influenced our conclusions.

Despite these limitations, the multiple lines of evidence presented here indicate that 2-OPRI observed in conjunction with CJD demonstrates typical clinicopathological features of SCJD, but a different biochemical profile. The relative abundance of 2-OPRI in multiple large-scale population genetic datasets and a lack of a family history of prion disease in these cases is reassuring. The extremely low penetrance of close to $0 \%$, with upper bounds of $95 \%$ CIs of below $2 \%$, suggest that 2 -OPRI is, at most, a very low-risk variant. There may also be non-PRNP genetic variants that affect penetrance [42]. Predictive clinical genetic testing for asymptomatic blood relatives is not likely to be justified, given the extremely modest increased lifetime risk. However, ongoing research of prion disease patients with 2-OPRI genetic variants and their family members will be helpful for informing and elucidating the pathogenic contribution from this rare genetic variant.

\section{Conclusions}

The 2-OPRI genetic variant does not appear to be a pathogenic mutation but may slightly increase risk of developing sporadic CJD. Cases of prion disease with the 2-OPRI genetic variant resemble sporadic CJD.

Author Contributions: N.B. acquired and analyzed data and drafted a significant portion of the manuscript. I.C. acquired and analyzed data and drafted a significant portion of the manuscript. T.H.M. analyzed data and drafted a significant portion of the manuscript. H.S. acquired and analyzed data. L.L.P.H. drafted a significant portion of the manuscript. C.S. acquired data and revised the manuscript. L.C. acquired and analyzed data. G.P. acquired and analyzed data. T.W.P. acquired and analyzed data. M.L.C. acquired and analyzed data. S.J.C. acquired and analyzed data. S.M. contributed to conception and design of the study, acquired and analyzed data, and drafted a significant portion of the manuscript. B.S.A. contribute to conception and design of the study, acquired and analyzed data, and drafted/edited the manuscript. All authors have read and agreed to the published version of the manuscript.

Funding: T.H.M. is supported by a Fellowship award from the Alzheimer's Society, UK (grant number 341 (AS-CTF-16b-007)) and by a CJD Support Network UK Research Support Grant. B.S.A. has received research funding from CDC, NIH, Ionis, the CJD Foundation, and Alector. SM is a National Institute for Health Research Senior Investigator. The UK studies were funded by the Biomedical Research Centre at University College London Hospitals NHS Foundation Trust and the Medical Research Council (UK).

Institutional Review Board Statement: The study was conducted according to the guidelines of the Declaration of Helsinki, and approved by the Institutional Review Board of University Hospitals Cleveland Medical Center (STUDY20201625), the Scotland A Research Ethics Committee (REC code 05/MRE00/63), and the University of Melbourne Human Research Ethics Committee (ethics approval number 1341074).

Informed Consent Statement: Informed consent was obtained from all subjects or their legal authorized representatives involved in the study. 
Acknowledgments: We are indebted to our patients and their families as well as to surveillance center staff. The National Prion Disease Pathology Surveillance Center is funded by the Centers for Disease Control and Prevention. This study was in part supported by the NIH NIA K99 AG068359 to I. Cali. As a trainee of the research education component (REC) of the Cleveland Alzheimer's Disease Research Center (CADRC), the work of I. Cali was also supported by the NIA P30 AG062428. This research was made possible through access to the data and findings generated by the 100,000 Genomes Project. The 100,000 Genomes Project is managed by Genomics England Limited (a wholly owned company of the Department of Health and Social Care). The 100,000 Genomes Project is funded by the National Institute for Health Research (NIHR) and NHS England. The Wellcome Trust, Cancer Research UK and the Medical Research Council have also funded research infrastructure. The 100,000 Genomes Project uses data provided by patients and collected by the National Health Service as part of their care and support. The National Prion Monitoring Cohort study and other research activities of the UK National Prion Clinic are supported by the NIHR's Biomedical Research Centre at UCL Hospitals NHS Foundation Trust and the Medical Research Council (UK). Simon Mead is an NIHR Senior Investigator. Tze How Mok was funded by the Alzheimer's Society (UK).

Conflicts of Interest: There are no competing interests for any author.

\section{References}

1. Takada, L.T.; Kim, M.-O.; Metcalf, S.; Gala, I.I.; Geschwind, M.D. Prion Disease. Handb. Clin. Neurol. 2018, 148, 441-464. [CrossRef]

2. Kim, M.-O.; Takada, L.T.; Wong, K.; Forner, S.A.; Geschwind, M.D. Genetic PrP Prion Diseases. Cold Spring Harb. Perspect. Biol. 2018, 10, a033134. [CrossRef] [PubMed]

3. Moore, R.A.; Herzog, C.; Errett, J.; Kocisko, D.A.; Arnold, K.M.; Hayes, S.F.; Priola, S.A. Octapeptide Repeat Insertions Increase the Rate of Protease-Resistant Prion Protein Formation. Protein Sci. 2006, 15, 609-619. [CrossRef]

4. Croes, E.; Theuns, J.; Houwing-Duisterma, J.; Dermaut, B.; Sleegers, K.; Roks, G.; Van den Broeck, M.; van Harten, B.; van Swieten, J.C.; Cruts, M.; et al. Octapeptide Repeat Insertions in the Prion Protein Gene and Early Onset Dementia. J. Neurol. Neurosurg. Psychiatry 2004, 75, 1166-1170. [CrossRef] [PubMed]

5. Goldfarb, L.G.; Brown, P.; Little, B.W.; Cervenáková, L.; Kenney, K.; Gibbs, C.J.; Gajdusek, D.C. A New (Two-Repeat) Octapeptide Coding Insert Mutation in Creutzfeldt-Jakob Disease. Neurology 1993, 43, 2392-2394. [CrossRef]

6. Van Harten, B.; Van Gool, W.A.; Van Langen, I.M.; Deekman, J.M.; Meijerink, P.H.; Weinstein, H.C. A New Mutation in the Prion Protein Gene: A Patient with Dementia and White Matter Changes. Neurology 2000, 55, 1055-1057. [CrossRef] [PubMed]

7. Collins, S.; Boyd, A.; Fletcher, A.; Gonzales, M.; McLean, C.A.; Byron, K.; Masters, C.L. Creutzfeldt-Jakob Disease: Diagnostic Utility of 14-3-3 Protein Immunodetection in Cerebrospinal Fluid. J. Clin. Neurosci. 2000, 7, 203-208. [CrossRef] [PubMed]

8. Hamlin, C.; Puoti, G.; Berri, S.; Sting, E.; Harris, C.; Cohen, M.; Spear, C.; Bizzi, A.; Debanne, S.M.; Rowland, D.Y. A Comparison of Tau and 14-3-3 Protein in the Diagnosis of Creutzfeldt-Jakob Disease. Neurology 2012, 79, 547-552. [CrossRef]

9. Foutz, A.; Appleby, B.S.; Hamlin, C.; Liu, X.; Yang, S.; Cohen, Y.; Chen, W.; Blevins, J.; Fausett, C.; Wang, H.; et al. Diagnostic and Prognostic Value of Human Prion Detection in Cerebrospinal Fluid. Ann. Neurol. 2017, 81, 79-92. [CrossRef]

10. Green, A.J.E. RT-QuIC: A New Test for Sporadic CJD. Pract. Neurol. 2019, 19, 49-55. [CrossRef] [PubMed]

11. Zerr, I.; Kallenberg, K.; Summers, D.M.; Romero, C.; Taratuto, A.; Heinemann, U.; Breithaupt, M.; Varges, D.; Meissner, B.; Ladogana, A.; et al. Updated Clinical Diagnostic Criteria for Sporadic Creutzfeldt Jakob Disease. Brain 2009, 132, $2659-2668$. [CrossRef] [PubMed]

12. Wadsworth, J.D.F.; Adamson, G.; Joiner, S.; Brock, L.; Powell, C.; Linehan, J.M.; Beck, J.A.; Brandner, S.; Mead, S.; Collinge, J. Methods for Molecular Diagnosis of Human Prion Disease. In Prions: Methods and Protocols; Lawson, V.A., Ed.; Methods in Molecular Biology; Springer: New York, NY, USA, 2017; pp. 311-346. ISBN 978-1-4939-7244-9.

13. Piazza, M.; Prior, T.W.; Khalsa, P.S.; Appleby, B. A Case Report of Genetic Prion Disease with Two Different PRNP Variants. Mol. Genet. Genomic Med. 2020, e1134. [CrossRef] [PubMed]

14. Goldfarb, L.G.; Brown, P.; McCombie, W.R.; Goldgaber, D.; Swergold, G.D.; Wills, P.R.; Cervenakova, L.; Baron, H.; Gibbs, C.J.; Gajdusek, D.C. Transmissible Familial Creutzfeldt-Jakob Disease Associated with Five, Seven, and Eight Extra Octapeptide Coding Repeats in the PRNP Gene. Proc. Natl. Acad. Sci. USA 1991, 88, 10926-10930. [CrossRef] [PubMed]

15. Kascsak, R.J.; Rubenstein, R.; Merz, P.A.; Tonna-DeMasi, M.; Fersko, R.; Carp, R.I.; Wisniewski, H.M.; Diringer, H. Mouse Polyclonal and Monoclonal Antibody to Scrapie-Associated Fibril Proteins. J. Virol. 1987, 61, 3688-3693. [CrossRef]

16. Zou, W.-Q.; Langeveld, J.; Xiao, X.; Chen, S.; McGeer, P.L.; Yuan, J.; Payne, M.C.; Kang, H.-E.; McGeehan, J.; Sy, M.-S.; et al. PrP Conformational Transitions Alter Species Preference of a PrP-Specific Antibody. J. Biol. Chem. 2010, 285, 13874-13884. [CrossRef]

17. Mauro, C.; Giaccone, G.; Piscosquito, G.; Lavorgna, A.; Nigro, M.; Di Fede, G.; Leonardi, A.; Coppola, C.; Formisano, S.; Tagliavini, F.; et al. A Novel Insertional Mutation in the Prion Protein Gene: Clinical and Bio-Molecular Findings. J. Neurol. Neurosurg. Psychiatry 2008, 79, 1395-1398. [CrossRef]

18. Cali, I.; Cracco, L.; Saracino, D.; Occhipinti, R.; Coppola, C.; Appleby, B.S.; Puoti, G. Case Report: Histopathology and Prion Protein Molecular Properties in Inherited Prion Disease With a De Novo Seven-Octapeptide Repeat Insertion. Front. Cell Neurosci. 2020, 14, 150. [CrossRef] [PubMed] 
19. Hill, A.F.; Joiner, S.; Wadsworth, J.D.; Sidle, K.C.; Bell, J.E.; Budka, H.; Ironside, J.W.; Collinge, J. Molecular Classification of Sporadic Creutzfeldt-Jakob Disease. Brain 2003, 126, 1333-1346. [CrossRef]

20. Cali, I.; Miller, C.J.; Parisi, J.E.; Geschwind, M.D.; Gambetti, P.; Schonberger, L.B. Distinct Pathological Phenotypes of CreutzfeldtJakob Disease in Recipients of Prion-Contaminated Growth Hormone. Acta Neuropathol. Commun. 2015, 3, 37. [CrossRef]

21. Cali, I.; Castellani, R.; Yuan, J.; Al-Shekhlee, A.; Cohen, M.L.; Xiao, X.; Moleres, F.J.; Parchi, P.; Zou, W.-Q.; Gambetti, P. Classification of Sporadic Creutzfeldt-Jakob Disease Revisited. Brain 2006, 129, 2266-2277. [CrossRef]

22. Cali, I.; Castellani, R.; Alshekhlee, A.; Cohen, Y.; Blevins, J.; Yuan, J.; Langeveld, J.P.M.; Parchi, P.; Safar, J.G.; Zou, W.-Q.; et al. Co-Existence of Scrapie Prion Protein Types 1 and 2 in Sporadic Creutzfeldt-Jakob Disease: Its Effect on the Phenotype and Prion-Type Characteristics. Brain 2009, 132, 2643-2658. [CrossRef]

23. Parchi, P.; Castellani, R.; Capellari, S.; Ghetti, B.; Young, K.; Chen, S.G.; Farlow, M.; Dickson, D.W.; Sima, A.A.; Trojanowski, J.Q.; et al. Molecular Basis of Phenotypic Variability in Sporadic Creutzfeldt-Jakob Disease. Ann. Neurol. 1996, 39, 767-778. [CrossRef]

24. Parchi, P.; Giese, A.; Capellari, S.; Brown, P.; Schulz-Schaeffer, W.; Windl, O.; Zerr, I.; Budka, H.; Kopp, N.; Piccardo, P.; et al. Classification of Sporadic Creutzfeldt-Jakob Disease Based on Molecular and Phenotypic Analysis of 300 Subjects. Ann. Neurol 1999, 46, 224-233. [CrossRef]

25. Minikel, E.V.; Vallabh, S.M.; Lek, M.; Estrada, K.; Samocha, K.E.; Sathirapongsasuti, J.F.; McLean, C.Y.; Tung, J.Y.; Yu, L.P.C.; Gambetti, P.; et al. Quantifying Prion Disease Penetrance Using Large Population Control Cohorts. Sci. Transl. Med. 2016, 8, 322. [CrossRef] [PubMed]

26. Mok, T.H.; Koriath, C.; Jaunmuktane, Z.; Campbell, T.; Joiner, S.; Wadsworth, J.D.F.; Hosszu, L.L.P.; Brandner, S.; Parvez, A.; Truelsen, T.C.; et al. Evaluating the Causality of Novel Sequence Variants in the Prion Protein Gene by Example. Neurobiol. Aging 2018, 71, 265.e1-265.e7. [CrossRef] [PubMed]

27. Vital, C.; Gray, F.; Vital, A.; Parchi, P.; Capellari, S.; Petersen, R.B.; Ferrer, X.; Jarnier, D.; Julien, J.; Gambetti, P. Prion Encephalopathy with Insertion of Octapeptide Repeats: The Number of Repeats Determines the Type of Cerebellar Deposits. Neuropathol. Appl. Neurobiol. 1998, 24, 125-130. [CrossRef] [PubMed]

28. Reiniger, L.; Mirabile, I.; Lukic, A.; Wadsworth, J.D.; Linehan, J.M.; Groves, M.; Lowe, J.; Druyeh, R.; Rudge, P.; Collinge, J.; et al. Filamentous White Matter Prion Protein Deposition Is a Distinctive Feature of Multiple Inherited Prion Diseases. Acta Neuropathol. Commun. 2013, 1, 8. [CrossRef]

29. Hill, A.F.; Joiner, S.; Beck, J.A.; Campbell, T.A.; Dickinson, A.; Poulter, M.; Wadsworth, J.D.F.; Collinge, J. Distinct Glycoform Ratios of Protease Resistant Prion Protein Associated with PRNP Point Mutations. Brain 2006, 129, 676-685. [CrossRef] [PubMed]

30. Mead, S.; Poulter, M.; Beck, J.; Webb, T.E.F.; Campbell, T.A.; Linehan, J.M.; Desbruslais, M.; Joiner, S.; Wadsworth, J.D.F.; King, A.; et al. Inherited Prion Disease with Six Octapeptide Repeat Insertional Mutation-Molecular Analysis of Phenotypic Heterogeneity. Brain 2006, 129, 2297-2317. [CrossRef] [PubMed]

31. Karczewski, K.J.; Francioli, L.C.; Tiao, G.; Cummings, B.B.; Alföldi, J.; Wang, Q.; Collins, R.L.; Laricchia, K.M.; Ganna, A.; Birnbaum, D.P.; et al. The Mutational Constraint Spectrum Quantified from Variation in 141,456 Humans. BioRxiv 2020, 531210. [CrossRef]

32. Minikel, E.V.; Zhao, H.T.; Le, J.; O’Moore, J.; Pitstick, R.; Graffam, S.; Carlson, G.A.; Kavanaugh, M.P.; Kriz, J.; Kim, J.B.; et al. Prion Protein Lowering Is a Disease-Modifying Therapy across Prion Disease Stages, Strains and Endpoints. Nucleic Acids Res. 2020, 48, 10615-10631. [CrossRef]

33. Parchi, P.; Strammiello, R.; Notari, S.; Giese, A.; Langeveld, J.P.M.; Ladogana, A.; Zerr, I.; Roncaroli, F.; Cras, P.; Ghetti, B.; et al. Incidence and Spectrum of Sporadic Creutzfeldt-Jakob Disease Variants with Mixed Phenotype and Co-Occurrence of PrPSc Types: An Updated Classification. Acta Neuropathol. 2009, 118, 659-671. [CrossRef]

34. Maddox, R.A.; Person, M.K.; Blevins, J.E.; Abrams, J.Y.; Appleby, B.S.; Schonberger, L.B.; Belay, E.D. Prion disease incidence in the United States: 2003-2015. Neurology 2020, 94, e153-e157. [CrossRef] [PubMed]

35. Collinge, J. Prion Diseases of Humans and Animals: Their Causes and Molecular Basis. Annu. Rev. Neurosci. 2001, 24, 519-550. [CrossRef] [PubMed]

36. Beck, J.A.; Poulter, M.; Campbell, T.A.; Adamson, G.; Uphill, J.B.; Guerreiro, R.; Jackson, G.S.; Stevens, J.C.; Manji, H.; Collinge, J.; et al. PRNP Allelic Series from 19 Years of Prion Protein Gene Sequencing at the MRC Prion Unit. Hum. Mutat. 2010, 31, E1551-E1563. [CrossRef]

37. Fischer, M.; Rülicke, T.; Raeber, A.; Sailer, A.; Moser, M.; Oesch, B.; Brandner, S.; Aguzzi, A.; Weissmann, C. Prion Protein $(\operatorname{PrP})$ with Amino-Proximal Deletions Restoring Susceptibility of PrP Knockout Mice to Scrapie. EMBO J. 1996, 15, 1255-1264. [CrossRef] [PubMed]

38. Prusiner, S.B.; Groth, D.F.; Bolton, D.C.; Kent, S.B.; Hood, L.E. Purification and Structural Studies of a Major Scrapie Prion Protein. Cell 1984, 38, 127-134. [CrossRef]

39. Wells, M.A.; Jackson, G.S.; Jones, S.; Hosszu, L.L.P.; Craven, C.J.; Clarke, A.R.; Collinge, J.; Waltho, J.P. A Reassessment of Copper(II) Binding in the Full-Length Prion Protein. Biochem. J. 2006, 399, 435-444. [CrossRef]

40. Kaski, D.N.; Pennington, C.; Beck, J.; Poulter, M.; Uphill, J.; Bishop, M.T.; Linehan, J.M.; O’Malley, C.; Wadsworth, J.D.F.; Joiner, S.; et al. Inherited Prion Disease with 4-Octapeptide Repeat Insertion: Disease Requires the Interaction of Multiple Genetic Risk Factors. Brain 2011, 134, 1829-1838. [CrossRef] 
41. Mead, S.; Webb, T.E.F.; Campbell, T.A.; Beck, J.; Linehan, J.M.; Rutherfoord, S.; Joiner, S.; Wadsworth, J.D.F.; Heckmann, J.; Wroe, S.; et al. Inherited Prion Disease with 5-OPRI: Phenotype Modification by Repeat Length and Codon 129. Neurology 2007, 69, 730-738. [CrossRef]

42. Jones, E.; Hummerich, H.; Viré, E.; Uphill, J.; Dimitriadis, A.; Speedy, H.; Campbell, T.; Norsworthy, P.; Quinn, L.; Whitfield, J.; et al. Identification of Novel Risk Loci and Causal Insights for Sporadic Creutzfeldt-Jakob Disease: A Genome-Wide Association Study. Lancet Neurol. 2020, 19, 840-848. [CrossRef] 